\title{
Progress in Refractory Metals Research
}

\author{
J. Ciulik
}

It has been a productive year in refractory metals research. We had a very interesting symposium at the 2009 TMS Annual Meeting in San Francisco. The Next Generation Superalloys and Beyond symposium, sponsored by the High Temperature Alloys Committee and the Refractory Metals Committee, included numerous refractory metals presentations. There is a considerable amount of work being done on Nb-Si-based alloys, Mo-Si-B alloys, and $\mathrm{Nb}-\mathrm{Ti}-\mathrm{Si}-\mathrm{Mo}-\mathrm{X}$ alloys, and I thoroughly enjoyed being at the meeting to see the results from the latest research on these alloys. Presentation abstracts are available on the TMS website if you weren't able to attend the meeting (www.tms.org/Meetings/Annual-09/ AM09home.aspx). If you're interested in the work presented, the authors would certainly like to hear from you. In this issue of $J O M$, we have three articles on refractory metals. The first describes Mo-Si-B and Co-Re alloy development, next is an overiew of the mechanical properties of a W-Re alloy and W-Re with HfC particles added, and the third covers the oxidation behavior of arc-cast Nb-20Mo-15Si-5B$20 \mathrm{Cr}$ alloy between $700^{\circ} \mathrm{C}$ and $1,300^{\circ} \mathrm{C}$.

In the first article, Martin Heilmaier et al. have provided us with an overview of two promising refractory metal systems: Mo-Si-B and Co-Re alloys. Both have potential as future high-temperature structural materials which can take us considerably above the temperature limits of nickel-based superalloys $\left(1,200^{\circ} \mathrm{C}\right)$, likely by $200^{\circ} \mathrm{C}$ or more due to the higher melting temperatures of the refractory metal alloys. In addition to overview descrip- tions of these two alloy systems, the authors have included microstructures, room-temperature mechanical properties, creep strength behavior, and oxidation resistance results, and compare the results to those from the CMSX-4 alloy currently used in high-temperature gas turbines (a rhenium-containing nickel-based single-crystal alloy). Their results indicate that at a $1,200^{\circ} \mathrm{C}$ service temperature, Mo-9Si-8B alloys provide substantial improvement. The Co-17Re-23Cr alloy did not perform as well, but both alloy systems appear to be promising with further microstructural and compositional improvements.

In the second article, Todd Leonhardt describes the microstructures and mechanical properties of $\mathrm{W}-25 \% \mathrm{Re}$ and $\mathrm{W}-24.5 \% \mathrm{Re}-2 \% \mathrm{HfC}$ alloys, tested in tension at room temperature, $1,371^{\circ} \mathrm{C}$, and $1,926^{\circ} \mathrm{C}$. The processing of these alloys is difficult, but the strength at elevated temperatures is substantially better than TZM alloy (a solid solution molybdenum-based alloy with titanium carbide and zirconium carbide particles, which is often used in hightemperature applications). With the addition of HfC particles, this tungstenrhenium alloy has an ultimate tensile strength at $1,926^{\circ} \mathrm{C}$ higher than 250 $\mathrm{MPa}$ and a yield strength higher than $130 \mathrm{MPa}$, making it an attractive alloy for high-temperature applications, even up to $2,000^{\circ} \mathrm{C}$. At such temperatures, the strengths of many refractory metal alloys are minimal.

In the third article, Julieta Ventura and S.K. Varma describe the short term (24 hour) and long term (seven 24-hour heating cycles) oxidation behavior of an arc-cast Nb-20Mo-15Si-
5B-20Cr alloy exposed to air at $700^{\circ} \mathrm{C}$ to $1,300^{\circ} \mathrm{C}$. Adding chromium to the $\mathrm{Nb}-\mathrm{Mo}-\mathrm{Si}-\mathrm{B}$ system is expected to improve the oxidation resistance of alloys through the formation of protective chromium-rich oxides. The results indicate that the formation of $\mathrm{CrNbO}_{4}$ improves the oxidation resistance above $1,000^{\circ} \mathrm{C}$. Prof. Varma's group has undertaken a long-term research effort to characterize the oxidation resistance of niobium-based alloys, and two previous articles about their work have been published in $J O M .{ }^{1,2}$

Our next TMS refractory metals meeting will be Refractory Metals and Alloys 2010 at the 2010 TMS Annual Meeting (February 14 through 18, in Seattle, Washington). Our symposium organizers, Brian Cockeram and Gary Rosak, would very much like to hear from you if you're interested in presenting. On the TMS website (www.tms.org /meetings/annual-10/AM10home. aspx) there is detailed information about the scope of the symposium and abstract submission deadlines. Presentation abstracts are currently being accepted, so please consider presenting your work at the Seattle meeting. I look forward to seeing you there.

\section{References}

1. B. Portillo, P. Kakarlapudi, and S.K. Varma, "The Possible Application of $\mathrm{Nb}-\mathrm{W}-\mathrm{Cr}$ Alloys in HighTemperature Air," JOM, 59 (6) (2007), pp. 46-49. 2. Maria D. Moricca and S.K. Varma, "High Temperature Oxidation Characteristics of Alloys from the $\mathrm{Nb}-\mathrm{W}-\mathrm{Cr}$ System with C Additions," JOM, 60 (7) (2008), pp. 6669

J. Ciulik is with the Mechanical Engineering Department of the University of Texas at Austin in Austin, Texas, and is the advisor to JOM from the Refractory Metals Committee of the Structural Materials Division of TMS. He can be reached at jciulik@mail.utexas.edu. 